\title{
Relationship of antral follicular blood flow velocity to superovulatory responses in ewes
}

\author{
M.E.F. Oliveira ${ }^{\mathrm{a}, *}$, P.M. Bartlewski ${ }^{\mathrm{b}}$, N. Jankowski ${ }^{\mathrm{b}}$, L.C. Padilha-Nakaghi ${ }^{\mathrm{a}}$, \\ L.G. Oliveira ${ }^{c}$, S.D. Bicudo ${ }^{\mathrm{d}}$, J.F. Fonseca ${ }^{\mathrm{e}}$, W.R.R. Vicente ${ }^{\mathrm{a}}$

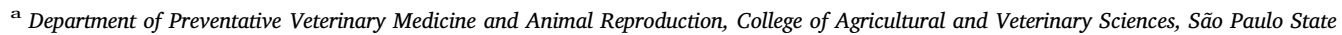 \\ University, Jaboticabal, São Paulo, 14.884-900, Brazil \\ b Department of Biomedical Sciences, Ontario Veterinary College, University of Guelph, Guelph, Ontario, N1G 2W1, Canada \\ ${ }^{\mathrm{c}}$ Department of Clinical and Veterinary Surgery, College of Agricultural and Veterinary Sciences, São Paulo State University, Jaboticabal, São Paulo, \\ 14.884-900, Brazil \\ d Department of Animal Reproduction and Veterinary Radiology, Faculty of Veterinary Medicine and Animal Science, São Paulo State University, \\ Botucatu, São Paulo, 18.618-970, Brazil \\ e Brazilian Agricultural Research Corporation-Embrapa Goats and Sheep, Coronel Pacheco, Minas Gerais, 36.155-000, Brazil
}

\section{A R T I C L E I N F O}

\section{Keywords:}

Superovulation

Sheep

Ovarian antral follicles

Color Doppler sonography

Blood flow velocity

\begin{abstract}
A B S T R A C T
The aim of this study was to examine the association between antral follicular blood flow velocity and the response of ewes to hormonal ovarian superstimulation. Ten Santa Inês ewes were subjected to a short- (7 days; Group 1) or long-term (13 days; Group 2) progesterone (CIDR*; InterAg, Hamilton, New Zealand) priming, and a superovulatory treatment with porcine folliclestimulating hormone (pFSH; Folltropin ${ }^{\circ} \mathrm{V}$; Bioniche Animal Health, Belleville, ON, Canada), given twice daily for four consecutive days in decreasing doses and initiated four or ten days after CIDR insertion, respectively. Embryos were recovered surgically seven days after the last pFSH dose. From one day prior to until the end of the pFSH regimen (Days -1 to 3), all ewes underwent daily transrectal ultrasonography of ovaries. The number of high-velocity pixels (HVPs; $0.055-0.11 \mathrm{~m} / \mathrm{s}$ or upper $50 \%$ of recordable velocities) on Day 1 correlated directly with the number of corpora lutea (CL; $r=0.92, P=0.0002)$ and of viable embryos $(r=0.77$, $P=0.01)$. Correlations were also recorded between the number of HVPs on Day 3 and the recovery rate $(r=-0.69, P=0.03)$, viability rate $(r=-0.64, P=0.05)$, and percentage of degenerated embryos $(\mathrm{r}=0.65, \mathrm{P}=0.04)$. The percentage of HVPs relative to the total area of ovarian cross section on Day 1 was correlated with the number of CL $(r=0.95, P<0.001)$ and of viable embryos $(r=0.85, P=0.002)$. This parameter on Day 3 was also correlated with the recovery rate $(r=-0.69, P=0.03)$. The percentage of HVPs relative to the total Doppler area on Day 0 was correlated with the recovery rate $(r=0.72, P=0.02)$. It can be concluded that sonographic assessment of high-velocity antral follicular blood flow has the makings of a useful non-invasive method to predict the outcome of the superovulatory treatment in ewes.
\end{abstract}

\section{Introduction}

Superovulation is the application of supraphysiological doses of exogenous gonadotropic hormones, such as follicle-stimulating

\footnotetext{
* Corresponding author at: Department of Preventative Veterinary Medicine and Animal Reproduction, College of Agricultural and Veterinary Sciences, São Paulo State University, Jaboticabal, SP, Via de acesso Professor Paulo Donato Castellane, s/n, 14.884-900, Brazil.

E-mail address: m.emiliafraoli@fcav.unesp.br (M.E.F. Oliveira).
} 
hormone (FSH), pregnant mare serum gonadotropin (PMSG), horse anterior pituitary extract (HAP) or human menopausal gonadotropin (hMG), to increase the number of ovulatory follicles and retrievable oocytes or embryos per cycle of treatment (Moore and Shelton, 1964; Ryan et al., 1991; Loi et al., 1998). In sheep, hormonal ovarian superstimulation is mainly used in multiple ovulation and embryo transfer (MOET) programs (Alwan et al., 1988; Loi et al., 1998; Shipley et al., 2007). Because there is a wide variety of both intrinsic and extrinsic factors that can affect the outcomes of superovulation, the intended result cannot always be achieved (Bartlewski et al., 2008a, 2008b, 2009, 2016; Quan et al., 2011). The age, breed, nutrition and reproductive status, type of gonadotropins used and the method of their administration are all known to have an influence on the success of superovulatory treatments (Bartlewski et al., 2008a, 2008b, 2009, 2016; Quan et al., 2011). The plethora of factors that can impinge on the results of hormonal ovarian superstimulation makes it difficult to predict its specific outcomes in individual animals. This unpredictability poses a frustrating limitation towards the use of superovulatory treatments in small ruminants.

An increase in uterine and ovarian blood supply is observed during superovulatory treatments of dairy cows and mares (Honnens et al., 2008, 2009; Bartlewski et al., 2016), and ovarian blood flow volume in mares is related to the effectiveness of superovulation; a positive correlation exists between the uterine artery pulsatility index and the number of recovered embryos (Witt et al., 2012; Bartlewski et al., 2016). Color Doppler sonography provides a valuable tool for detecting and monitoring dynamic changes in the vascular network and blood flow in various reproductive organs and tissues, including ovarian antral follicles (Fleischer and Andreotti, 2005). During antral follicular growth, there is an increased blood flow to the outer layer (theca) of the follicle wall proper (Murdoch et al., 1983; Lass and Brinsden, 1999; Matsui and Miyamoto, 2009). Hence, in cattle, the color Doppler sonography could effectively be used to assess the number of emerging antral follicles and the thickness of the theca layer (Matsui and Miyamoto, 2009), which is one of the markers of follicular health (Singh and Adams, 2000). Elevated blood flow velocity is also associated with the terminal development of ovulatory follicles Lass and Brinsden (1999). A significant rise in ovarian blood flow associated with the growth of multiple ovulatory-sized follicles was a reliable predictor of the superovulatory responses in mares (Witt et al., 2012) and humans (Zaidi et al., 1996) undergoing hormonal ovarian superstimulation. A similar study conducted in Santa Inês ewes revealed the existence of a significant positive correlation between antral follicular blood flow estimates on the final day of the superovulatory protocol and the number of unfertilized eggs (Oliveira et al., 2014). Those earlier studies were inclusive of all detectable Doppler blood flow signals, failing to distinguish between different blood velocities. However, the resulting ovarian Doppler images clearly depicted a distribution of blood flow that was highly heterogeneous (Fig. 1), with most images exhibiting a wide range of follicular blood flow velocities (Oliveira et al., 2014). Blood flow velocity is significantly less as blood moves across a capillary bed than in the vessels leading to and exiting from the capillaries (i.e., arterioles and venules; Bartlewski et al., 2016) and a large proportion of this flow is not detectable with color Doppler sonography (Fig. 1). These are compelling reasons to perform retrospective analyses on the data from our earlier ovine study (Oliveira et al., 2014) with the intent of determining whether correlations exist between highvelocity flowing blood (i.e., arteriolar/venular compartment; Fig. 1) in ovarian antral follicles and superovulatory yields. We hypothesized that such measures of ovarian follicular blood flow intensity determined with computer-aided analyses of Doppler ultrasonographic images would be indicative of impending superovulatory responses in ewes.

\section{Material and methods}

The present study used the original data collected by Oliveira et al. (2014) but with the more discriminating image analysis of blood flow velocities captured in Doppler sonographic images of ovaries. Ten Santa Inês ewes underwent either a short- (7-day, Group 1) or long-term (13-day, Group 2) progesterone treatment (Controlled internal drug release (CIDR) inserts; InterAg, Hamilton, New Zealand) to synchronize estrus and ovulation (Fig. 2). The short- and long-term estrous synchronization groups, each consisting of five sheep, received twice daily injections of porcine follicle stimulating hormone (pFSH; Folltropin -V; Bioniche Animal Health, Belleville, ON, Canada) for four consecutive days, in decreasing doses (40, 40, 30, 30, 20, 20, 10 and 10 mg i.m), starting on Day 4 and Day 10 after CIDR insertion, respectively. The ewes in both groups received an injection of a prostaglandin $F_{2 \alpha}$ analogue (Dcloprostenol, Prolise ; Arsa, Argentina; $37.5 \mu \mathrm{g}$ i.m.) on Day 0 and at the time of CIDR withdrawal, and an injection of equine chorionic gonadotropin (eCG, Novormon; Syntex, Buenos Aires, Argentina) on CIDR removal day.

The ova/embryos were recovered surgically 7 days after the end of the superovulatory treatment. Laparotomy was performed under general anesthesia. Each uterine horn was exposed and flushed with $\sim 40 \mathrm{ml}$ of flushing media (DPBS ${ }^{\oplus}$; Cultilab, Campinas, SP, Brazil) pre-warmed to $37{ }^{\circ} \mathrm{C}$. Flushing media were injected with a 20G catheter inserted at the proximal portion of the uterine horn and were collected using a no. 10 Foley catheter inserted at the uterine bifurcation. All recovered eggs and morulae/blastocysts were enumerated, and the embryos were transferred into holding media (Holding Plus; ; Cultilab, Campinas, SP, Brazil). All embryos that were graded using the International Embryo Transfer Society (IETS) criteria with Grade 1 being excellent, Grade 2-good/fair, Grade 3-poor and Grade 4-degenerated (Lindner and Wright, 1993; Rubianes et al., 1995). Embryo grades 1-3 were regarded as transferrable quality embryos. Morphological evaluation was performed under a stereomicroscope at 40x magnification.

Beginning one day prior to and continuing on all four days of the pFSH superovulatory treatment, transrectal Doppler ultrasonography was performed on all animals studied. Daily ultrasonographic examinations utilized the color Doppler and B-mode ultrasound scanner (MyLab VET 30; Esaote, Genoa, Italy) connected to a stiffened, variable frequency (6-8 MHz), linear-array transducer and were performed by one experienced operator. Ewes were examined in a standing position, and the abdominal wall was gently compressed to facilitate the visualization of the ovaries. Hydrosoluble contact gel was used to lubricate the rectum and transducer. The settings of the scanner (Doppler sampling frequency (PRF) $=1.4 \mathrm{kHZ}$ and color gain $=70 \%$ or just below the background noise level recorded in a motionless animal) remained constant for the duration of the study.

Still ultrasonographic images containing cross sections with the strongest Doppler signal for each ovary were analyzed. The 

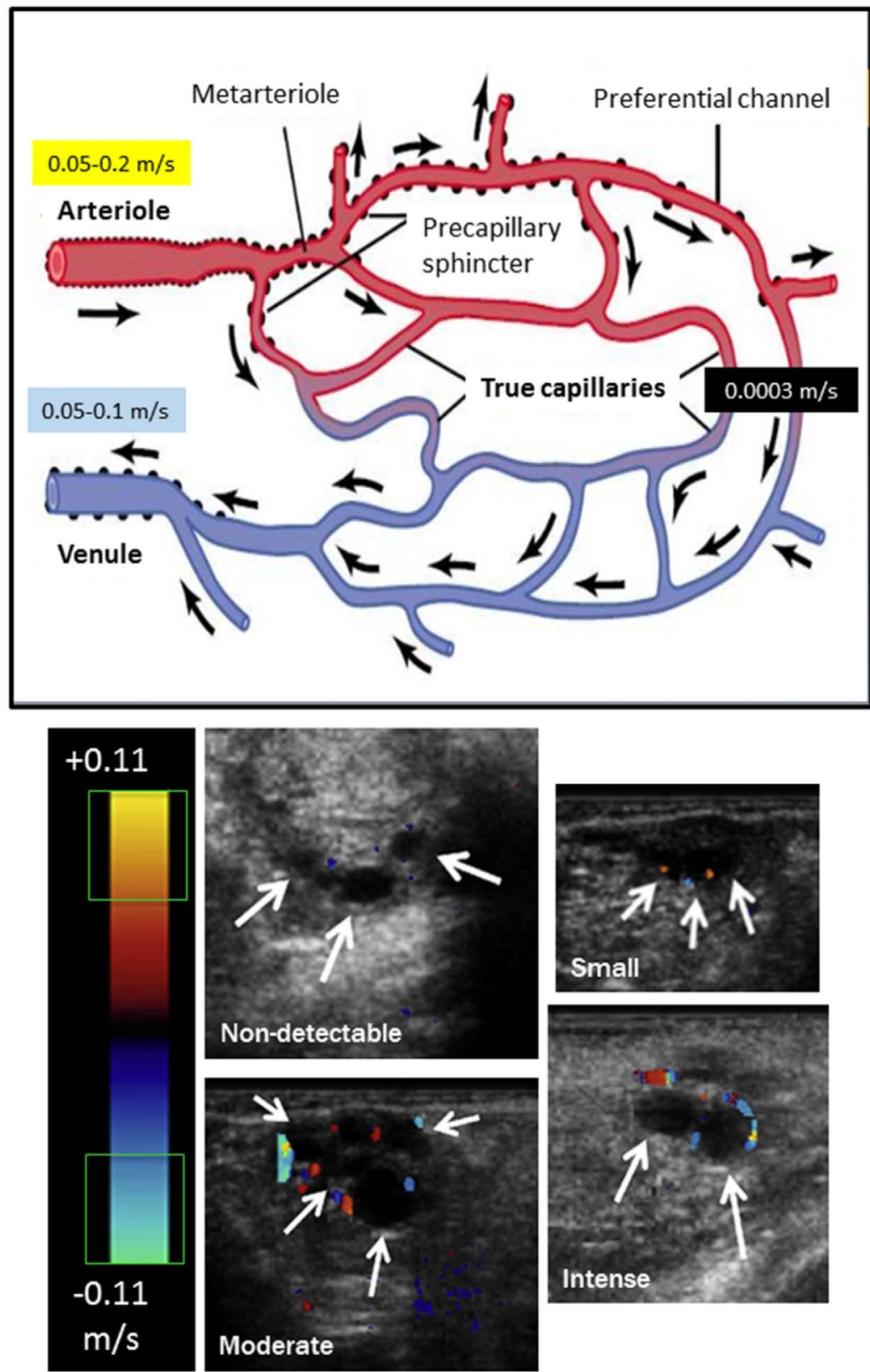

Fig 1. A diagrammatic representation of blood flow velocities in capillary beds (upper panel), and examples of color Doppler images recorded transrectally before and during the superovulatory porcine follicle-stimulating hormone (pFSH) treatment of ten Santa Inês ewes and depicting ovarian images with non-detectable, small, moderate and intense high-velocity $(0.055-0.11 \mathrm{~m} / \mathrm{s}$; denoted by green rectangles) follicular blood flow. White arrows indicate antral follicles.

velocity scale bar on each Doppler image was divided into 64 visibly distinct rows of colors (Fig. 1). The velocities in the top onequarter (16 rows) and the bottom one-quarter (16 rows) of the scale bar were then isolated. The numbers of pixels in the ultrasonogram of the ovary corresponding to colors in the top and bottom portions of the scale bar were enumerated using ImageProPlus analytical software (Media Cybernetics Inc., San Diego, CA, USA). The "Count/Size" function was utilized to tally the number of pixels in the ovary that fell into the selected color range; the estimated size of the pixel was $0.17 \mathrm{~mm}$. The number of pixels that corresponded to the colors in these selected regions of the color scale bar was deemed "high-velocity pixels" (HVPs). After obtaining the number of HVPs for each image, the average number of such pixels in both ovaries of each sheep was calculated, for each of the five days, and all results analyzed on a per animal basis. Additionally, the percentages of HVPs relative to total ovarian area (HVPs/TA x 100\%) and relative to total Doppler area (HVPs/DA x 100\%) were calculated. Comparisons between the short-term (Group 1) and long-term estrous synchronization protocol groups (Group 2) were examined with Student $t$ test (superovulatory yields) or two-way repeated-measures analysis of variance (RM ANOVA; changes in quantitative image attributes over the 5-day 


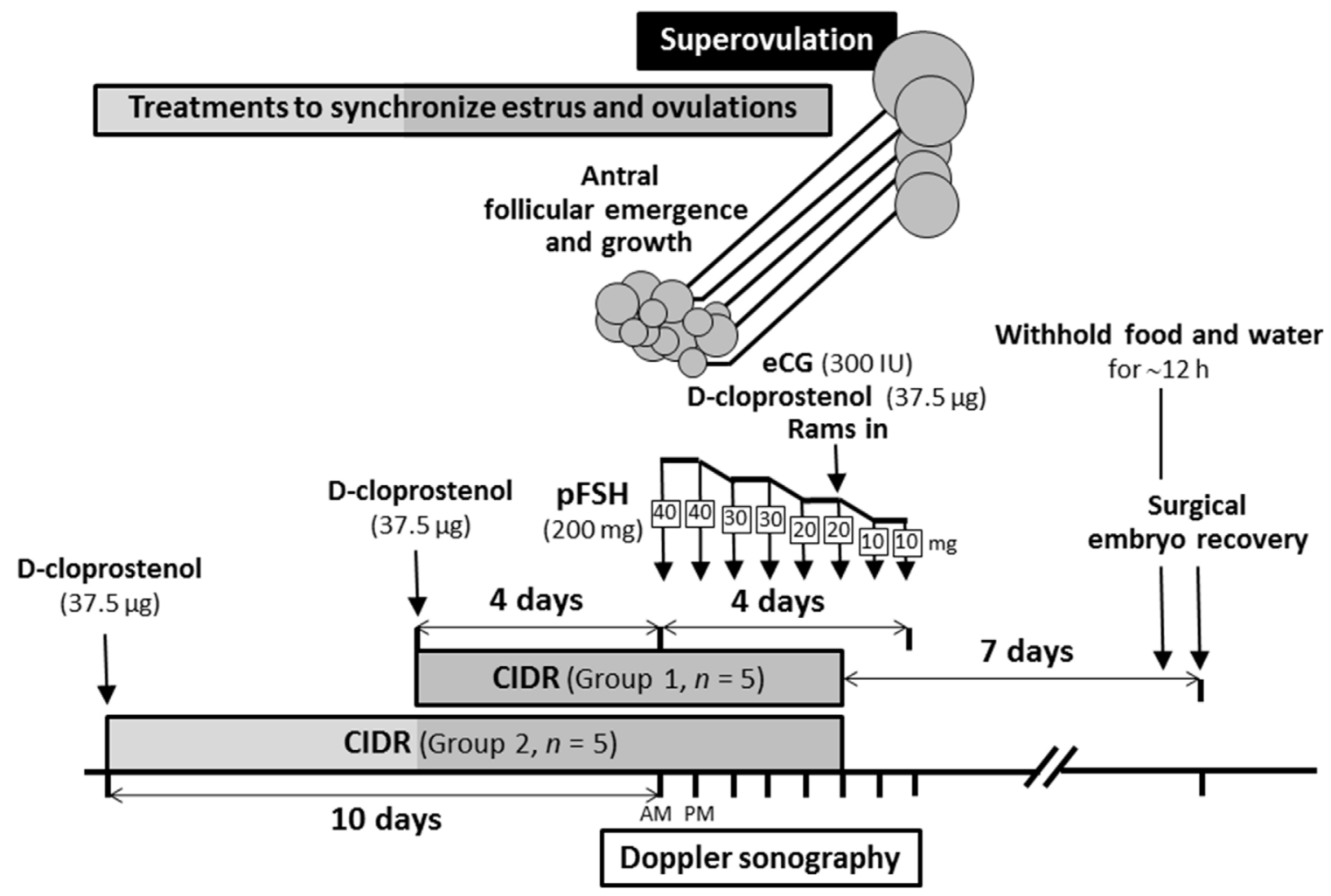

Fig. 2. A schematic of the experimental protocol including the timing of the estrous synchronization protocols, superovulatory treatments and color Doppler sonography of ovaries in Santa Inês ewes.

scanning period). Correlations among the estimates of HPVs on each day and superovulatory responses in the ewes of the present study (listed in Table 1) were tested by a simple linear regression. All results are given as mean \pm standard error of the mean (mean \pm SEM). $P$ value $\leq 0.05$ was considered statistically significant.

\section{Results}

Superovulatory responses in the ewes of the present study are summarized in Table 1. All ewes ovulated and had corpora lutea (CL) detected at laparotomy 7 days post-treatment. A mean of $3.6 \pm 1.7$ viable embryos (Grades 1-3) per donor ewe were obtained in this study. Thirty percent of all collections contained no viable embryos. In seventy percent of ewes, fewer than the average number of transferable quality embryos were collected. Sixty percent of ewes had degenerated (Grade 4) embryos and sixty percent of animals had unfertilized eggs. Significant positive correlations were found between the numbers of detected CL and all recovered

Table 1

Superovulatory responses after a multiple-dose, 4-day porcine follicle-stimulating hormone (pFSH) treatment in Santa Inês ewes undergoing the short- term (7 days, Group 1) or long-term (13 days, Group 2) progesterone-based estrous synchronization protocol.

\begin{tabular}{|c|c|c|c|c|c|c|c|c|}
\hline Group & No. of CL & $\begin{array}{l}\text { No. of viable } \\
\text { embryos } \\
\text { (Grades 1-3) }\end{array}$ & $\begin{array}{l}\text { No. of } \\
\text { degenerated } \\
\text { embryos (Grade 4) }\end{array}$ & $\begin{array}{l}\text { No. of } \\
\text { unfertilized } \\
\text { eggs }\end{array}$ & $\begin{array}{l}\text { No. of } \\
\text { recovered } \\
\text { structures }\end{array}$ & $\begin{array}{l}\text { Recovery rate } \\
(\%)\end{array}$ & Viability rate (\%) & $\begin{array}{l}\text { Degenerated } \\
\text { embryos (\%) }\end{array}$ \\
\hline \multirow[t]{5}{*}{1} & 8 & 2 & 3 & 3 & 8 & 100 & 25 & 37.5 \\
\hline & 8 & 0 & 2 & 3 & 5 & 62.5 & 0 & 40 \\
\hline & 6 & 4 & 0 & 1 & 5 & 83.3 & 80 & 0 \\
\hline & 10 & 1 & 0 & 6 & 7 & 70 & 14.3 & 0 \\
\hline & 26 & 18 & 0 & 1 & 19 & 73.1 & 94.7 & 0 \\
\hline \multirow[t]{5}{*}{2} & 10 & 6 & 3 & 0 & 9 & 90 & 66.7 & 33.3 \\
\hline & 15 & 2 & 8 & 0 & 10 & 66.7 & 20 & 80 \\
\hline & 5 & 3 & 1 & 0 & 4 & 80 & 75 & 25 \\
\hline & 12 & 0 & 0 & 10 & 10 & 83.3 & 0 & 0 \\
\hline & 11 & 0 & 7 & 0 & 7 & 63.6 & 0 & 100 \\
\hline Mean \pm SEM & $11.1 \pm 1.9$ & $3.6 \pm 1.7$ & $2.4 \pm 0.9$ & $2.4 \pm 1.0$ & $8.4 \pm 1.3$ & $77.2 \pm 3.9$ & $37.6 \pm 11.8$ & $31.6 \pm 11.1$ \\
\hline
\end{tabular}



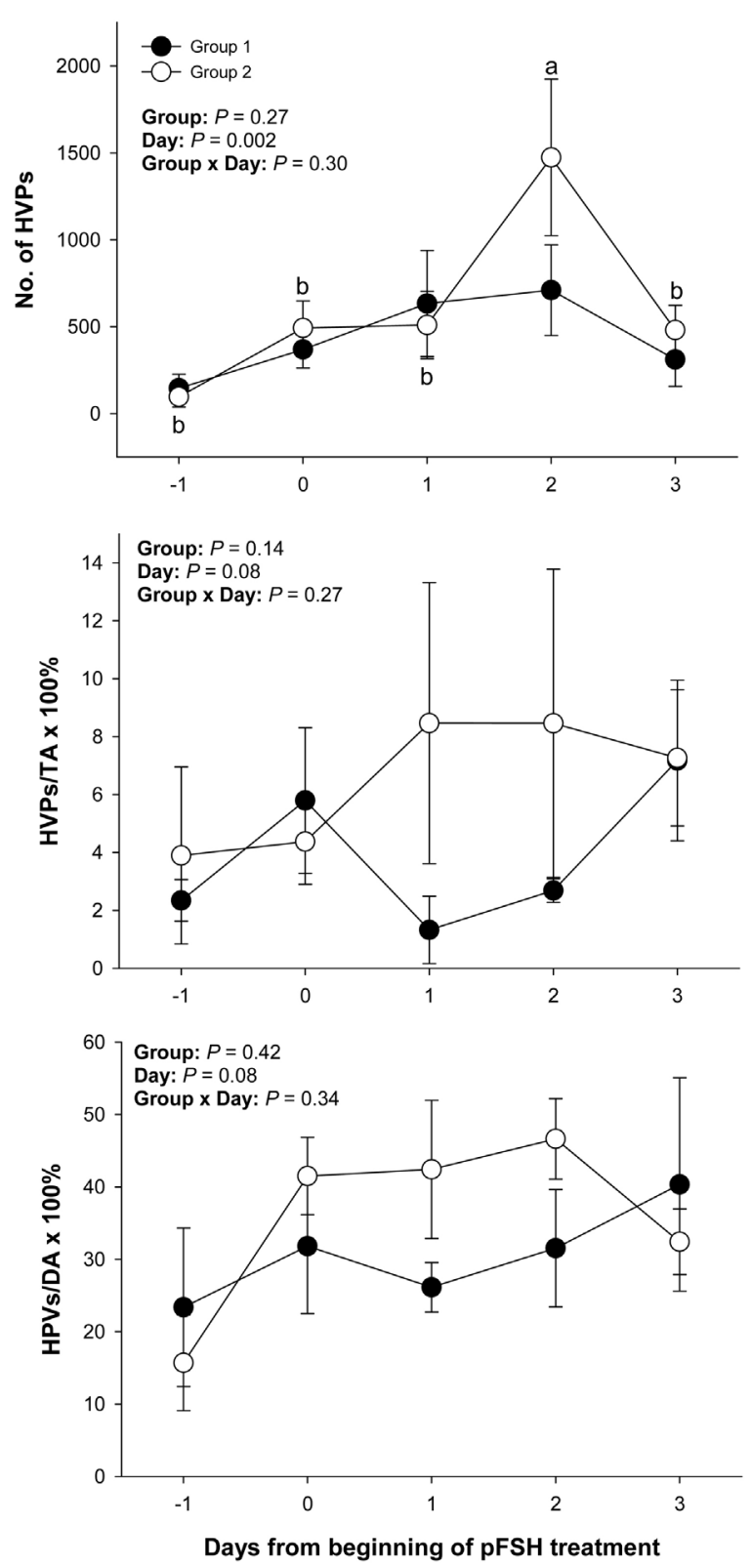

Fig. 3. Summary of the number of high-velocity pixels (HVPs) and the relative color Doppler areas (percentage of total ovarian cross section: HVPs/TA $x$ 100\% and of total Doppler signal area: HVPs/DA x 100\%) in ten Santa Inês ewes that underwent the multiple-dose, porcine follicle-stimulating hormone (pFSH) treatment preceded by a short-term (7 days, Group 1) or long-term progesterone-based estrous synchronization protocol (13 days, Group 2).

structures (embryos of all classes plus unfertilized eggs; ( $r=0.97, P<0.001$ ), and between the numbers of CL and transferrable quality embryos $(r=0.76, P=0.01)$.

There was no significant difference between the two groups of ewes in the mean number of high-velocity pixels (HVPs) in the ovarian Doppler images obtained from one day before until the end of pFSH treatment (Days -1 to 3; Fig. 3). On Day 2, the number of HVPs was significantly greater from all the other days in Group 2 ewes. No significant differences were found between the two groups of ewes and over time for the percentages of HVPs relative to the total ovarian area (HPVs/TA x 100\%) nor the percentages of HVPs relative to the total Doppler area (HPVs/DA x 100\%; Fig. 3).

Significant correlations were found between the number of HVPs on Day 1 and the number of corpora lutea (CL; $r=0.92$, $P<0.001)$, number of all recovered structures $(r=0.87, P=0.001)$, and number of viable embryos $(r=0.77, P=0.01)($ Tables 1-3 ). Significant correlations were also recorded between the number of HVPs on Day 3 and the recovery rate $(r=-0.69$, $P=0.03)$, viability rate $(r=-0.64, P=0.05)$, and percentage of degenerated embryos $(r=0.65, \mathrm{P}=0.04)$. The percentage of HVPs relative to total ovarian area (HVPs/TA x 100\%) on Day 1 was significantly correlated with the number of CL $(r=0.95$, $P=0.00002)$, number of all recovered structures $(r=0.92, P=0.0002)$, and number of viable embryos $(r=0.85, P=0.002)$ of 
Table 2

A summary of quantitative sonographic (color Doppler) blood flow parameters in superovulated Santa Inês ewes ( $n=10$ ) in which the 4-day (Days 0-3) porcine follicle-stimulating hormone (pFSH) treatment was applied at the end of a short-term (7 days, Group 1) or long-term (13 days, Group 2) progesterone-based estrous synchronization protocol. HVPs: number of high-velocity $(0.055-0.11 \mathrm{~m} / \mathrm{s})$ pixels per ewe; DA: total Doppler signal area; TA: total ovarian cross-sectional area.

\begin{tabular}{|c|c|c|c|c|c|}
\hline \multirow[t]{2}{*}{ Group } & \multicolumn{2}{|l|}{ No. of HVPs } & \multicolumn{2}{|c|}{ HVPs/TA x 100\% } & \multirow{2}{*}{$\begin{array}{l}\text { HVPs/DA x 100\% } \\
\text { Day } 0\end{array}$} \\
\hline & Day 1 & Day 3 & Day 1 & Day 3 & \\
\hline \multirow[t]{5}{*}{1} & 329 & 225 & 1.2 & 1.2 & 67.0 \\
\hline & 182 & 894 & 1.5 & 11.2 & 21.2 \\
\hline & 334 & 0 & 3.6 & 0 & 12.6 \\
\hline & 483 & 310 & 3.8 & 2.7 & 27.5 \\
\hline & 1837 & 127 & 17.6 & 1.4 & 30.7 \\
\hline \multirow[t]{5}{*}{2} & 319 & 0 & 2.7 & 0 & 54.0 \\
\hline & 1281 & 583 & 8.1 & 3.3 & 24.0 \\
\hline & 270 & 593 & 1.7 & 6.5 & 45.3 \\
\hline & 396 & 363 & 4.5 & 2.6 & 49.0 \\
\hline & 338 & 852 & 3.1 & 8.7 & 35.2 \\
\hline Mean \pm SEM & $577 \pm 171$ & $395 \pm 103$ & $4.8 \pm 1.6$ & $3.8 \pm 1.2$ & $36.6 \pm 5.3$ \\
\hline
\end{tabular}

the superovulatory treatment. This parameter on Day 3 of the superovulatory treatment was also negatively correlated with the recovery rate $(r=-0.69, P=0.03)$. Lastly, the percentage of HVPs relative to the total Doppler area (HVPs/DA x 100\%) on Day 0 was positively correlated with the recovery rate $(r=0.72, P=0.02)$.

\section{Discussion}

The ability to predict the outcomes of superovulatory treatment during its initial stages would be extremely beneficial in terms of both ethical and practical senses. Knowing that a particular ewe is likely to be a poor responder to superovulatory stimulation could spare the animal from undergoing unnecessary treatment and procedures including the surgery to aspirate ovarian antral follicles or to collect embryos. In addition, the ability to predict the outcome of such a procedure before its completion could prevent unnecessary time and resources spent on animals that will not produce the desired amount of competent oocytes or transferable quality embryos.

While research into correlations between ovarian follicular blood flow and responses to superovulatory hormonal treatments has yielded useful and beneficial results in numerous species, up until this point the same type of results remains to be seen in sheep specifically. Earlier studies have indicated that analyzing the numbers of small antral follicles prior to superovulatory treatment and the assessment of ovarian follicular blood flow pre-treatment can both be useful indicators of superovulatory outcomes in cattle (Witt et al., 2012). These findings led to a study previously conducted in Santa Inês ewes, which attempted to determine the relationship between the estimates of follicular blood flow and superovulatory responses but had rather limited success; the only significant correlations found were between color Doppler signal recorded on the final day of the pFSH treatment and the number/percentage of unfertilized eggs (Oliveira et al., 2014).

The present finding that the quantity of "fast" blood flow in ovarian antral follicles, especially one day after the beginning of the superovulatory treatment (Day 1), is positively correlated with the ovulation rate and numbers of viable embryos presents a very

Table 3

A summary of significant correlations between the Doppler signal estimates and superovulatory responses in ten Santa Inês ewes subjected to the 4-day superovulatory porcine follicle-stimulating hormone (pFSH) treatment. HVPs: number of high-velocity $(0.055-0.11 \mathrm{~m} / \mathrm{s}$ ) pixels per ewe; DA: total Doppler signal area; TA: total ovarian cross-sectional area.

\begin{tabular}{lll}
\hline Input $(\mathrm{x})$ variable & Output (y) variable & Regression equation \\
\hline Day 0 HVPs/DA x 100\% & Recovery rate (\%) ${ }^{\mathrm{a}}$ & $\mathrm{y}=58.0+0.5 \mathrm{x}$ \\
Day 1 no. of HVPs & No. of CL & $\mathrm{y}=5.3+0.01 \mathrm{x}$ \\
Day 1 no. of HVPs & No. of recovered structures & $\mathrm{y}=4.5+0.007 \mathrm{x}$ \\
Day 1 no. of HVPs & No. of viable embryos & $\mathrm{y}=-0.8+0.008 \mathrm{x}$ \\
Day 1 HVPs/TA x $100 \%$ & No. of CL & $\mathrm{y}=5.5+1.2 \mathrm{x}$ \\
Day 1 HVPs/TA x $100 \%$ & No. of recovered structures & $\mathrm{y}=4.6+0.8 \mathrm{x}$ \\
Day 1 HVPs/TA $100 \%$ & No. of viable embryos & $\mathrm{y}=-0.9+0.9 \mathrm{x}$ \\
Day 3 no. of HVPs & Recovery rate $(\%)$ & $\mathrm{y}=87.5-0.03 \times$ \\
Day 3 no. of HVPs & Viability rate $(\%)^{\mathrm{c}}$ & $\mathrm{y}=66.6-0.07 \mathrm{x}$ \\
Day 3 no. of HVPs & Degenerated embryos $(\%)$ & $\mathrm{y}=4.0+0.1 \mathrm{x}$ \\
Day 3 HVPs/TA x $100 \%$ & Recovery rate $(\%)$ & $\mathrm{y}=85.4-2.2 \mathrm{x}$ \\
\hline
\end{tabular}

${ }^{a}$ Number of all recovered structures/no. of CL x 100\%.

b Viable and degenerated embryos + unfertilized eggs.

${ }^{\mathrm{c}}$ Number of viable embryos/number of CL x $100 \%$. 
useful tool for predicting superovulatory responses; this association permits very early selection of good responders. Multiple correlations found between the numbers of high-velocity pixels on the last day of pFSH treatment (i.e., negative correlation between HVPs and the recovery rate as well as the positive correlation between HVPs and the percentages of degenerated embryos) are equally useful predictors of superovulatory outcomes in individual animals. In knowing that the increased amount of high-velocity blood flow observed in ovarian antral follicles on Day 3 can be associated with some undesirable superovulatory outcomes, practitioners and researchers can alternate their selection of animals for surgical embryo flushing to account for this. In addition, since significant positive correlations were found between the number of HVPs per total ovarian area (HVPs/TA x 100\%) on Day 1 and the number of corpora lutea and recovered structures, this particular finding can possibly be generalized to sheep of the same breed and similar age but varying in ovarian and follicular dimensions at the time of superovulatory treatment. This is because in the quantitative science, the relative change or difference (proportion) is used to compare two quantities, while taking into consideration the "sizes" of the variables being compared (Bennett and Briggs, 2005). In a similar fashion, the significant negative correlations between the proportion of HVPs relative to total ovarian area on Days 1 and 3 of the superovulatory treatment and the number of viable embryos or the recovery rate, respectively, can potentially be generalized onto a wider range of sheep as well. Since this is merely a supposition, more research is needed to confirm or refute the existence of such quantitative relationships in ewes. It was somewhat surprising though to find that the only significant correlation when analyzing the HVPs as a percentage of the total Doppler area was between that parameter on Day 0 and the recovery rate. This finding suggests that the proportion of high-velocity blood flow on the first day of the superovulatory protocol is only indicative of the efficiency with which both unfertilized eggs and embryos can be recovered post-treatment.

The amount of capillary blood flow to both ovulatory and atretic antral follicles in sheep has been vastly studied using radiolabeled microspheres in anaesthetized and conscious sheep, with inconsistent findings. Some studies suggested that capillary blood flow did not differ between atretic and non-atretic follicles of the same size and was not related to their steroidogenic activity (Bruce and Moor, 1976), whereas others indicate that blood supply to follicular theca cells in antral follicles showing advanced stages of atresia was significantly less compared with that in healthy follicles (Carson et al., 1986). Our results indicate that high-velocity blood flow is actually the "two-faced" marker of antral follicular health and oocyte competence. One day after the commencement of the superovulatory protocol, high-velocity blood flow appears to be an indicator of high ovulation rate and transferrable embryo yields. This is in agreement with our earlier observations that the number of growing antral follicles detected ultrasonographically $12 \mathrm{~h}$ after the first pFSH dose is positively correlated with superovulatory responses in ewes (Bartlewski et al., 2008). This observation also suggests that high-velocity blood flow is associated with the presence of healthy (non-atretic) ovine antral follicles. Alternatively, high-velocity blood flow on the final day of the superovulatory treatment appears to be indicative of poor recovery rates and diminished embryo viability. It is attractive to speculate that negative correlations between fast follicular blood flow and superovulatory outcomes reflect the elevated delivery of certain factors such as nitric oxide and an array of pro-apoptotic proteins (Sanchez and Smitz, 2012; Oliveira et al., 2014) that are detrimental to the survival and quality of ovarian follicular cells and oocytes.

Various metrics of high-velocity antral follicular blood flow one day after the beginning of the superovulatory protocol are indicative of ovulatory responses and embryo quality in the ewes of the present study. This fact can also be interpreted to suggest that high-velocity follicular blood flow and oocyte competence early during the application of superovulation are interdependent and both remain important determinants of superovulatory success. Additional projections of the expected numbers of unfertilized eggs (Oliveira et al., 2014) as well as embryo viability and recovery rates can be based on the assessment of antral follicular blood flow on the final day of the 4-day superovulatory protocol (Day 3). In some instances, there exist apparent discrepancies between the projected and actual results, especially for those variables that are influenced by surgical skills (e.g., recovery rates) or multiple intrinsic factors (e.g., embryo viability). Therefore, continued improvements to all aspects of superovulatory protocols will not only enhance the superovulatory yields but also our ability to more accurately predict their outcomes using color Doppler sonography of ovaries.

Future analyses aimed to quantify the ovarian follicular blood flow based on even more specific velocities are also warranted. Arteriolar blood flow tends to be faster than that in venules (Witt et al., 2012). This concept can be applied to the analysis of ovarian Doppler images to further separate the blood flow into arteriolar and venular, which could provide even more precise information on ovarian follicular blood supply and perfusion.

In summary, the results of this study indicate that estimation of specific antral follicular blood flow velocities can provide an insight into the results of the hormonal superovulatory treatment in the ewe. By analyzing both the absolute and relative amounts of high-velocity follicular blood flow in ovarian antral follicles of ewes it was possible to predict certain outcomes of the superovulatory procedures, which is a useful tool in the application of MOET, both in commercial operations and for reproductive research. It would now be interesting and justified to examine whether or not similar relationships can be seen during hormonal ovarian superstimulation in other mammalian species including women undergoing controlled gonadotropin treatments for infertility.

\section{Conflict of interest}

None to declare.

\section{Acknowledgements}

Funding for this study was provided by the São Paulo Research Foundation (FAPESP; MEFO), Natural Sciences and Engineering Research Council of Canada, and the Department of Biomedical Sciences, University of Guelph (PMB). 


\section{References}

Alwan, S.F., Boland, M.P., Gordon, I., 1988. Superovulation and oocyte recovery in the ewe. Theriogenology 29, $1143-1148$.

Bartlewski, P.M., Alexander, B.D., King, W.A., 2008a. Ovarian and endocrine determinants of superovulatory responses in anestrous ewes. Small Rumin. Res. 75, $210-216$.

Bartlewski, P.M., Alexander, B.D., Rawlings, N.C., Barrett, D.M.W., King, W.A., 2008b. Ovarian responses, hormonal profiles and embryo yields in anoestrous ewes superovulated with Folltropin ${ }^{\circ}-\mathrm{V}$ after pretreatment with medroxyprogesterone acetate (MAP)-releasing vaginal sponges and a single dose of oestradiol-17 $\beta$ ( $\mathrm{E}_{2}$ 17ß). Reprod. Dom. Anim. 43, 299-307.

Bartlewski, P.M., Fuerst, K.J., Alexander, B.D., King, W.A., 2009. Systemic concentrations of endogenous and exogenous FSH in anoestrous ewes superstimulated with Folltropin -V. Reprod. Dom. Anim. 44, 353-358.

Bartlewski, P.M., Seaton, P., Oliveira, M.E.F., Kridli, R.T., Murawski, M., Schwarz, T., 2016. Intrinsic determinants and predictors of superovulatory yields in sheep: circulating concentrations of reproductive hormones, ovarian status and antral follicular blood flow. Theriogenology 86, 130-143.

Bennett, J., Briggs, W., 2005. Using and Understanding Mathematics: A Quantitative Reasoning Approach, 3rd ed. Boston, Pearson ISBN 0-321-22773-5.

Bruce, N.W., Moor, R.M., 1976. Capillary blood flow to ovarian follicles, stroma, and corpora lutea of anaesthetized sheep. J. Reprod. Fertil. 46, 299-304.

Carson, R., Findlay, J., Mattner, P., Brown, B., 1986. Relative levels of thecal blood flow in atretic and non-atretic ovarian follicles of the conscious sheep. Aust. J. Exp. Biol. Med. Sci. 64, 381-387.

Fleischer, A.C., Andreotti, R.F., 2005. Color Doppler sonography in obstetrics and gynecology. Expert Rev. Med. Device 2, 605.

Honnens, A., Niemann, H., Paul, V., Meyer, H.H., Bollwein, H., 2008. Doppler sonography of the uterine arteries during a superovulatory regime in cattle: uterine blood flow in superovulated cattle. Theriogenology 70, 859-867.

Honnens, A., Niemann, H., Herzog, K., Paul, V., Meyer, H.H., Bollwein, H., 2009. Relationships between ovarian blood flow and ovarian response to eCG-treatment of dairy cows. Anim. Reprod. Sci. 113, 1-10.

Lass, A., Brinsden, P., 1999. The role of ovarian volume in reproductive medicine. Hum. Reprod. Update 13, $256-266$.

Lindner, G.M., Wright, R.W., 1993. Bovine embryo morphology and evaluation. Theriogenology 40, 713-724.

Loi, P., Ptak, G., Dattena, M., Ledda, S., Naitana, S., Cappai, P., 1998. Embryo transfer and related technologies in sheep reproduction. Reprod. Nutr. Dev. 38, 615-628. Matsui, M., Miyamoto, A., 2009. Evaluation of ovarian blood flow by color Doppler ultrasound: practical use for reproductive management in the cow. Vet. J. 181, $232-240$.

Moore, N.W., Shelton, J.N., 1964. Response of the ewe to a horse anterior pituitary extract. J. Reprod. Fertil. 7, 79-87.

Murdoch, W.J., Nix, K.J., Dunn, T.G., 1983. Dynamics of ovarian blood supply to periovulatory follicles of the ewe. Biol. Reprod. 28, $1001-1006$.

Oliveira, M.E.F., Feliciano, M.A.R., D'Amato, C.C., Oliveira, L.G., Bicudo, S.D., Fonseca, J.F., Vicente, W.R.R., Visco, E., Bartlewski, P.M., 2014. Correlations between ovarian follicular blood flow and superovulatory responses in ewes. Anim. Reprod. Sci. 144, 30-37.

Quan, F., Zhang, Z., Hua, S., Zhao, X., Zang, Y., 2011. Multiple factors affecting superovulation in Poll Dorset in China. Reprod. Dom. Anim. 46, 39-44.

Rubianes, E., Ibarra, D., Ungerfeld, R., Carbajal, B., de Castro, T., 1995. Superovulatory responses in anestrous ewes is affected by the presence of a large follicle. Theriogenology 43, 465-472.

Ryan, J.P., Hunton, J.R., Maxwell, W.M.C., 1991. Increased production of sheep embryos following superovulation of merino ewes with a combination of pregnant mare serum gonadotrophin and follicle stimulating hormone. Reprod. Fertil. Dev. 3, 551-560.

Sanchez, F., Smitz, J., 2012. Molecular control of oogenesis. Mol. Basis Dis. 1822, 1896-1912.

Shipley, C.F.B., Buckrell, B.C., Mylne, M.J.A., Pollard, J., Hunton, J.R., 2007. Artificial insemination and embryo transfer in sheep. Curr. Ther. Large Anim. Theriogenol. 2, 629-641.

Singh, J., Adams, G., 2000. Histomorphometry of dominant and subordinate bovine ovarian follicles. Anat. Rec. 258, 58-70.

Witt, M.C., Bollwein, H., Probst, J., Baackmann, C., Squires, E.L., Sieme, H., 2012. Doppler sonography of the uterine and ovarian arteries during a superovulatory program in horses. Theriogenology 77, 1406-1414.

Zaidi, J., Barber, J., Kyei-Mensah, A., 1996. Relationship of ovarian stromal blood flow at baseline ultrasound to subsequent follicular response in an in vitro fertilization program. J. Obstet. Gynaecol. 88, 779-784. 